$\mathrm{Oz}$

Volume 5

Article 13

$1-1-1983$

\title{
A Tale of Two Duchies: An Architectural Primer
}

Bob Burnham

William C. Miller

Follow this and additional works at: https://newprairiepress.org/oz

(c) (i) $\Theta \Theta$

This work is licensed under a Creative Commons Attribution-Noncommercial-No Derivative Works 4.0 License.

\section{Recommended Citation}

Burnham, Bob and Miller, William C. (1983) "A Tale of Two Duchies: An Architectural Primer," Oz: Vol. 5. https://doi.org/10.4148/2378-5853.1066

This Article is brought to you for free and open access by New Prairie Press. It has been accepted for inclusion in Oz by an authorized administrator of New Prairie Press. For more information, please contact cads@k-state.edu. 
Bob Burnham

William C. Miller

"A Tale of Two Duchies" is a series of four short episodic problems given in the Architectural Design Studio (ADS 1) course during the 1982 fall semester at Kansas State University. ADS 1 is the first studio course in the professional program; it occurs in the third year or junior level of a fiveyear curriculum. The students enrolled have completed two years in the University's preprofessional program where the studio courses have concentrated on the development of graphic skills and general design concerns.

Since ADS 1 is the student's first purely "architectural" studio, an attempt was made to devise an architectural primer which would help the students achieve four objectives;

1. To explore the essence and solution range for a series of architectural elements and ordering types common to architecture of all periods.

2. To learn to modify the characteristics of the elements and ordering types to accommodate a particular application.

3. To practice the molding of selected elements into an architectural whole.

4. To learn to analyze particular elements, types and specific models for what they may say about current architectural responses.

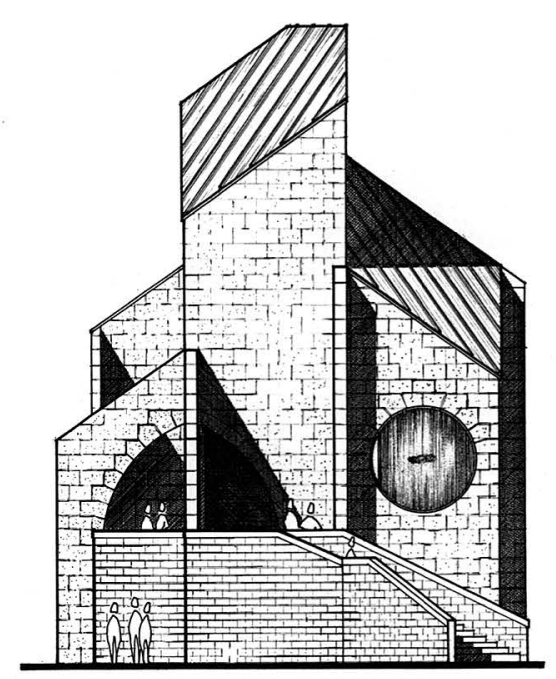

1

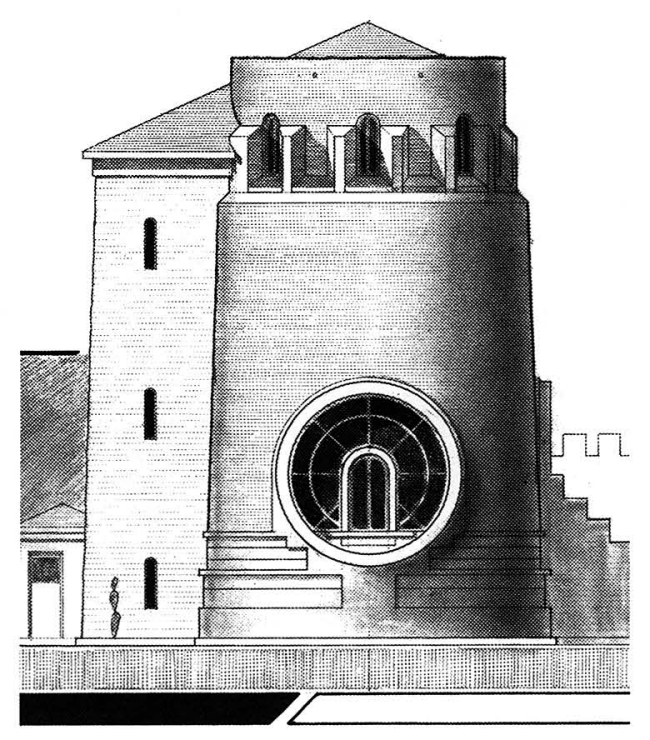

2
The four episodic problems comprising "A Tale of Two Duchies" are sequential, but are interspersed between longer design exercises which address broader architectural concerns and which also act as foils to the more specialized and focused short problems. In addition, the episodic problems have stringent presentation requirements-primarily line drawings accurately rendering the edges, patterns, materials and surfaces being represented. The number of required drawings is reduced to the minimum necessary to communicate the solution, yet encourages a high level of craftsmanship and detail development in the presentations.

"A Tale of Two Duchies" is an architectural fairytale. The story's setting - the Duchies of Curd and Whey - has both ancient and current temporal qualities. The characters of Duke David III of Curd and Duchess Martha of Whey were devised to be comfortably familiar, yet exotically removed by their fairytale setting. They must deal with problems containing the elements of love, hate, elation, disappointment, birth, and death. Similarly, the architectural problems established by their life situations contain elements such as columns, walls, roofs, windows, doors, staircases and entries. The fairytale setting seemed an ideal way to bring these elements into sharp focus for the students. 
This is a synopsis of the four episodes:

Episode 1 - Status Quo: Whey and Curd are longtime enemies, though they were founded by the same family. As the story opens, the Tower of Curd is destroyed by a fire during the inauguration of Duke David III. The new tower must serve a dual function: accommodate the throne room with its associated activities of government, and provide surveillance of Whey, located across the river.

Episode 2 - Love's Labors Gained: Duke David meets Duchess Martha of Whey at a Waterway Maintenance Conference and they fall in love. Since they are supposed to be enemies, a secret trysting place is needed. A cave or grotto was selected as the architectural type for this problem. It is located in a ruined rampart on the Wheyian side of the river.
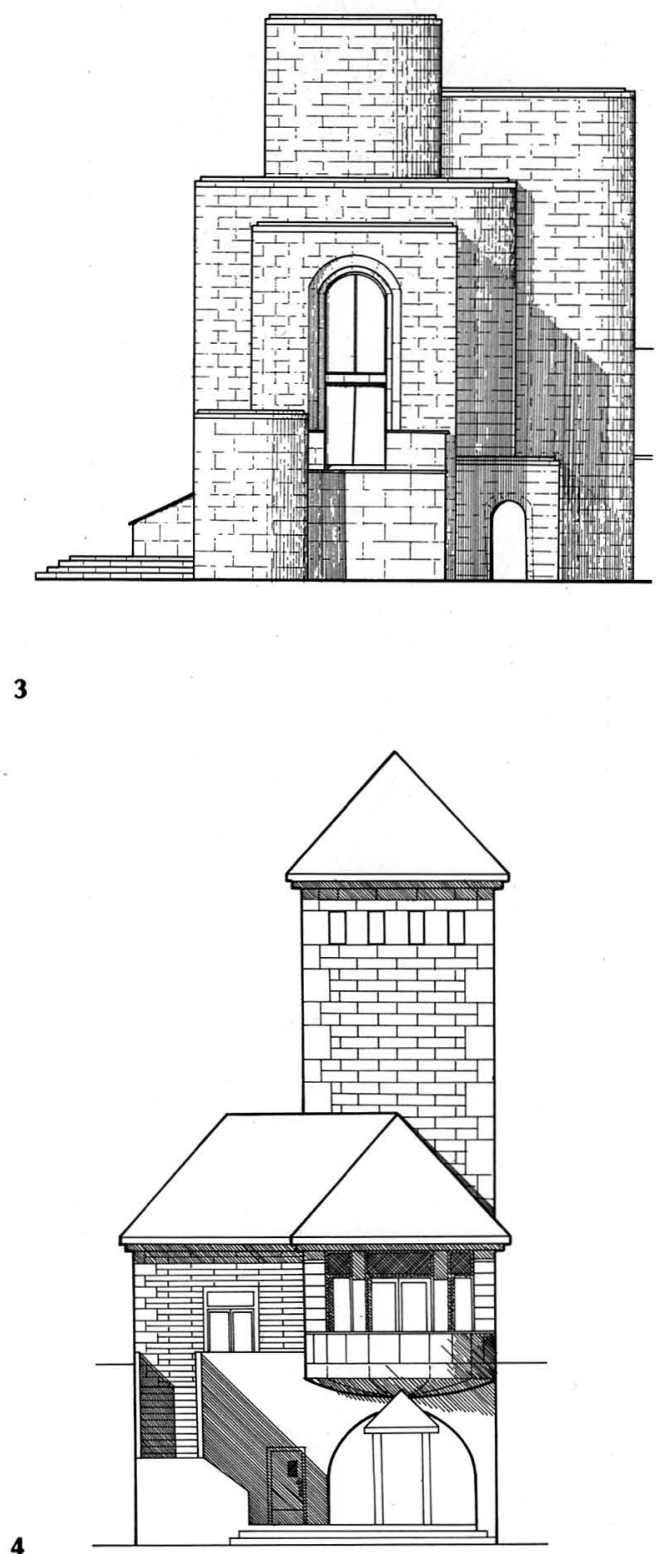

Episode 3 - The Duchies United: David and Martha decide to marry; the required design is of a chapel and garden court to be located on an island in the river separating the two kingdoms.

Episode 4 - Retreat: Twenty years after their marriage, Duke David is killed in a tragic accident, and
Martha decides to abdicate her throne and seek refuge in a c o n ve $n t-t$ y pe retreat. The problem calls for use of passive solar energy concepts and design criteria.

Each problem invokes different methods of addressing the design and selecting an ordering mechanism, a differing set of elements to be incorporated into the solution, and markedly different architectural qualities in both form and space.

Status Quo involves archetypal elements which have clear identity as objects: the tower, the giant stair, the great window and the throne. They invite manipulation because of their object qualities. Students pick them up in their minds and push and pull to see what these ideal objects will do or be. This action extends into a natural design approach in which the elements are assembled and molded into a whole, an approach encouraged by the natural hierarchy among the elements, with the tower being dominant. It is possible in this exercise to gain an awareness of the essential idea or "soul" underlying an element (or design). A tower, for example, is a building element which puts a person in a position of overviewing or commanding the space it dominates. Its essence is tied to its power to extend man's physical capabilities of defense and sight: a warrior on a tower distinguishes friend from foe and tosses a rock on the latter; a lady in a tower sees her lover and tosses him a kiss. For this essence, the Sears Tower in its immensity is perhaps less a tower than the residential towers of Urbino. The very direct process employed in this episode results in very conventional but fairly polished tower images (Figures 1-4) 


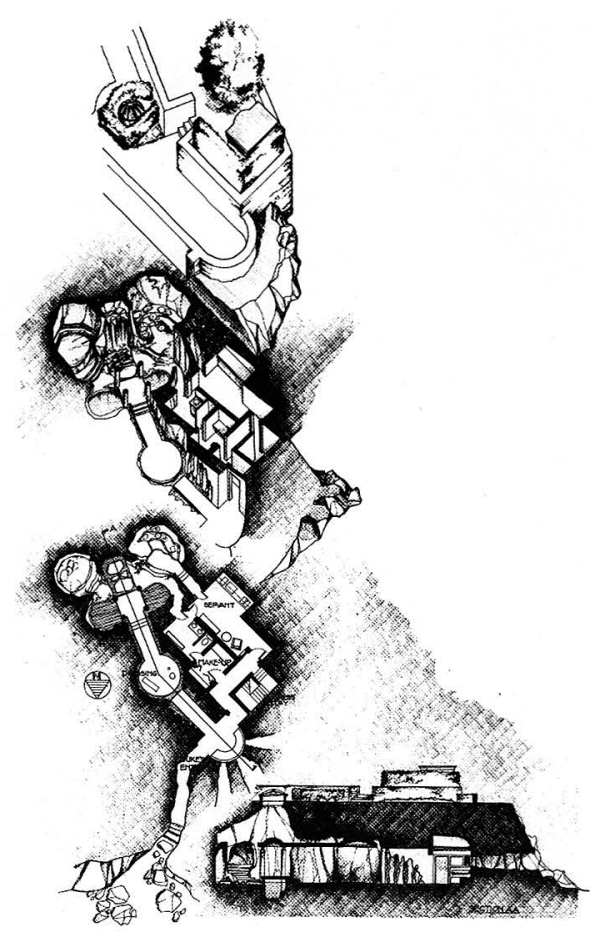

5

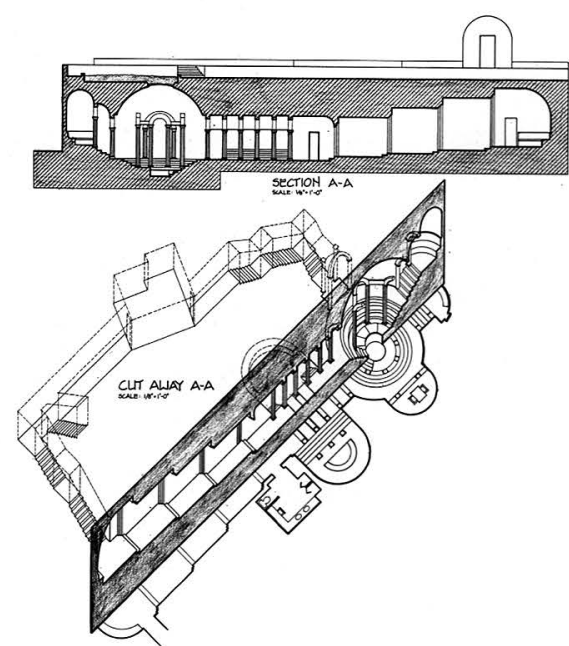

In Love's Labors Gained, the key elements are spaces rather than forms. Beginning students come to the idea of space after the idea of form and are in no hurry to manipulate spaces as work begins. Some students wonder what there is to manipulate, and others are baffled by the problem of how to simulate space as it may be studied. Actually the elements involved do own less dramatic qualities in this episode. 62 The more perceptive students

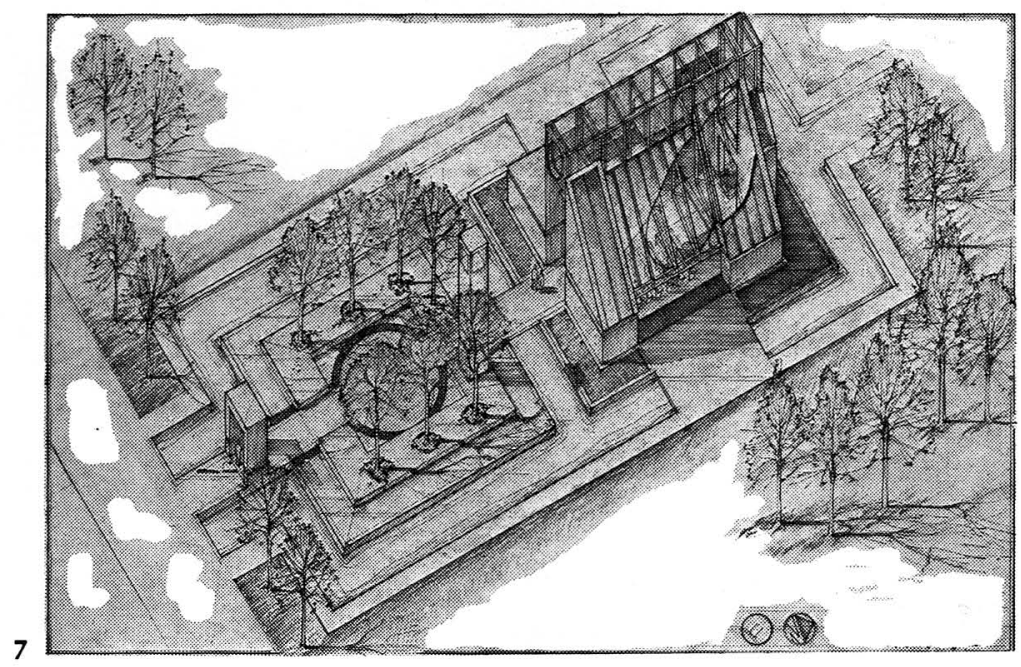

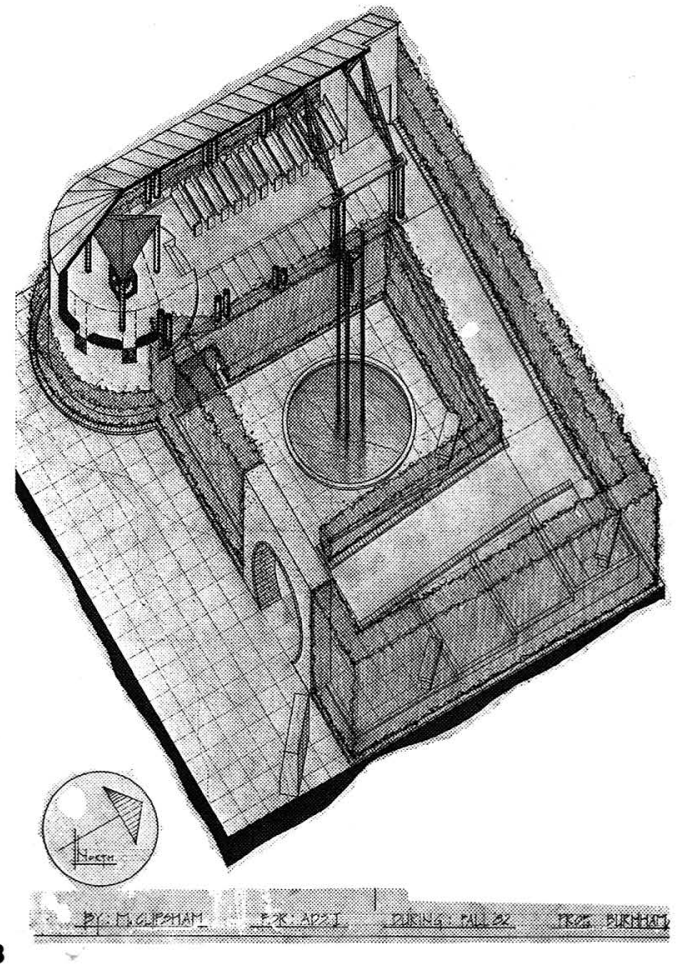

soon realize that distinctive designs will not be made in this instance by mechanical assembly and molding of the elements. An idea evocative of the purpose or meaning of the place is necessary for the response. Two of the more successful responses shown here rely on the ideas of movement ritualized in spatial progression and marked transformation of worlds as organizing concepts (Figures 5-6).
In Duchies United, the elements of a centralized garden court and a simple processional chapel pose a clear formal problem. How can a central space and a processional space/form be combined in a single design? This challenge and the requirement to engage component and surface development in the response are sufficient direction to stimulate intense activity. Lessons learned in the earlier exercises appear in the responses. Two of them seem to derive primarily from explorations of the properties of the elements (Figures 7-8). Two others seem to be more strongly motivated by particular movement scenarios (Figures 9-10). 

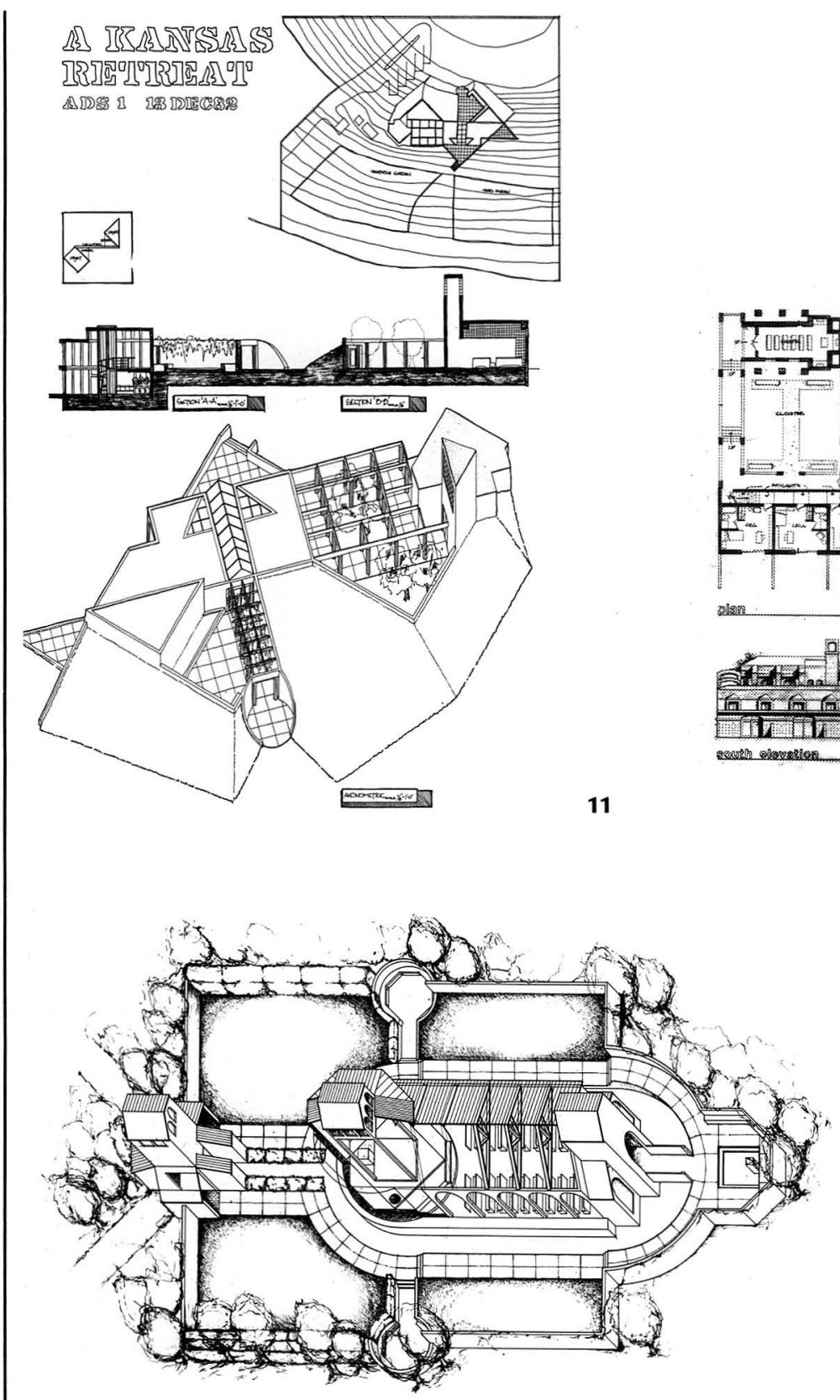

The final episode, Retreat, carries many of the requirements of the preceding exercises and is therefore the most complex. The given elements are not as dramatic as those in Episode 1. The qualities which can be applied to a response are more diverse than those appropriate for Episode 2. A formal problem is not identified in this assignment; students have to begin by identifying elements and organizing principles implicit in the
11

10

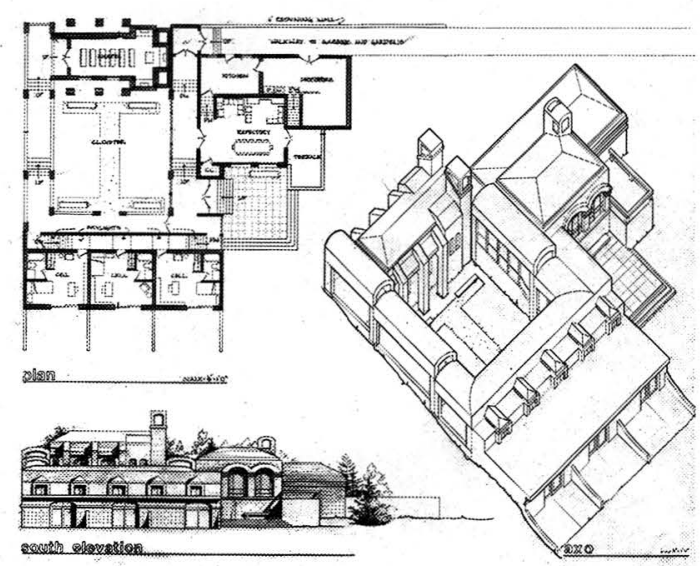

13
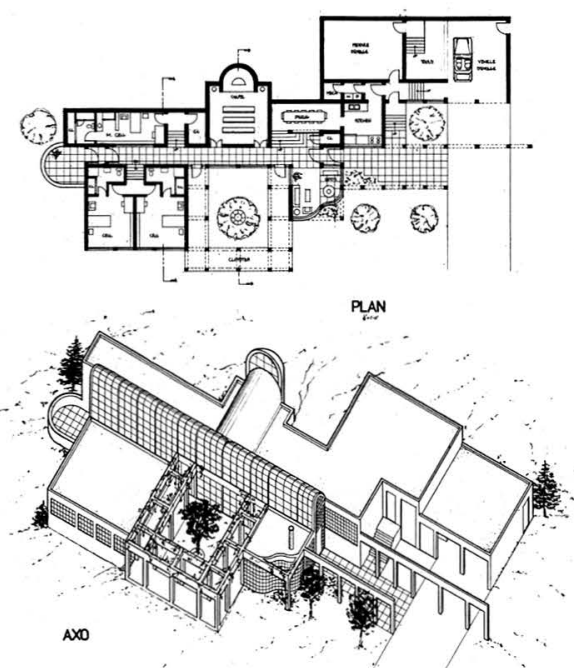

12

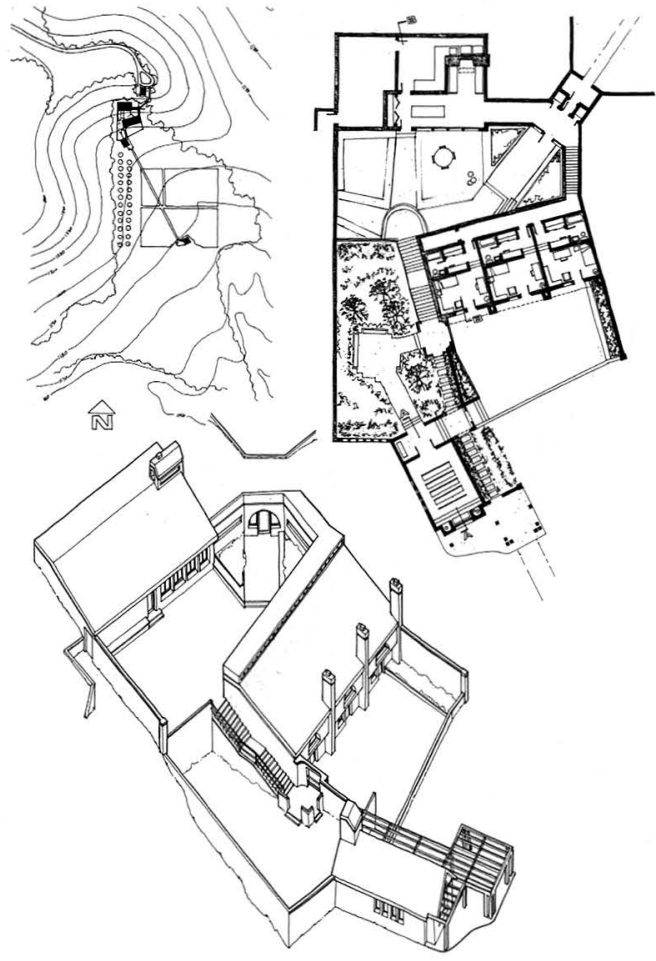

building type, establishing general qualities which might be appropriate, and discovering any formal problems which might be key to their understanding. The additional requirement of an energy conservative response contributes both contraints and ordering principles to the solutions. The responses reflect this increase in complexity (Figures 11-14).
Through these exercises, students are introduced to a variety of architectural and landscape elements, to ideas of composition and planning, and to methods for approaching design problems. These exercises involve dreams and reality. Most important, the process can demonstrate that the two realms are interdependent, not mutually exclusive.
LIST OF ILLUSTRATIONS

1. Tower, Linda Hall

2. Tower, Joe Cantrell

3. Tower, Tim Kitchens

4. Tower, Douglas Dulac

5. Trysting place, Mark Banholzer

6. Trysting place, Larry Irsik

7. Chapel, Doug Pierce

8. Chapel, Mark Clipsham

9. Chapel, Mark Banholzer

10. Chapel, Tom Larson

11. Retreat, James Chibnall

12. Retreat, Dan Himmelberg

13. Retreat, Stan Anderson

14. Retreat, Mark Banholzer 